Ng et al., Afr J Tradit Complement Altern Med. (2014) 11(2):315-318

\title{
IN-VITRO SCREENING OF MALAYSIAN HONEY FROM DIFFERENT FLORAL SOURCES FOR ANTIBACTERIAL ACTIVITY ON HUMAN PATHOGENIC BACTERIA
}

\author{
Wen-Jie Ng ${ }^{\text {a,b* }}$, Khai-Wei Ken ${ }^{\text {a }}$, Roshani-Vijaya Kumar ${ }^{\text {a }}$,Hemamalani Gunasagaran ${ }^{\text {a }}$, Vanaysha Chandramogan ${ }^{\text {a }}$ \\ and Ying-Yee Lee ${ }^{\mathrm{a}}$
}

\author{
${ }^{\mathrm{a}}$ Faculty of Science, ${ }^{\mathrm{b}}$ Centre for Biodiversity Research, Universiti Tunku Abdul Rahman, Perak, Malaysia \\ *Email:ngwj@utar.edu.my
}

\begin{abstract}
Background: Different researches on therapeutic effects of honey have been conducted in different regions; however the study on the potential antibacterial activity of Malaysian honey is still limited. In this study, antibacterial activities of different monofloral honey samples were tested against several common human pathogenic bacteria.

Materials and Methods: The well-diffusion method, minimum inhibitory concentrations (MIC) and minimum bactericidal concentration (MBC) techniques were employed to investigate the putative antibacterial activity of Malaysian monofloral honey from Koompassia excelsa (Becc.) Taub (Tualang), Melaleuca cajuputi Powell (Gelam) and Durio zibethinus Murr. (Durian). Honey samples were tested against Staphylococcus aureus ATCC6518 and ATCC25923, Staphylococcus epidermidis ATCC12228, Enterococcus faecium LMG16192, Enterococcus faecalis LMG16216 and ATCC29212, Escherichia coli ATCC25922, Salmonella enterica serovar Typhimurium ATCC14028 and Klebsiella pneumoniae ATCC13883.

Results: Marked variations were observed in the antibacterial activity of these honey samples. Durian honey failed to produce substantial antibacterial activity, whereas Tualang and Gelam honey showed a spectrum of antibacterial activity with their growth inhibitory effects against all of the tested bacterial species including vancomycin-resistant enterococci (VRE).

Conclusion: Present findings suggested Gelam honey possesses highest antibacterial effect among the tested Malaysian honey samples.
\end{abstract}

Keywords: Honey; monofloral; antibacterial; well-diffusion method; VRE

\section{Introduction}

Honey is a viscous, sugary, translucent, yellowish brown or light yellow liquid, where it deposited in the honey comb. Honey bees (Apis spp.) suck out the nectar from flowers and deposit in the stomach where the nectar blends with protein and enzymes of the bee, which is then being converted into honey. The antibacterial activity of honey was first recognized in 1892 by van Ketel (Dustmann, 1979). Recent years, honey has been selected for the treatments of bacterial infections by medical profession, especially with the emergence and continuous development of antibiotic resistance of pathogenic bacteria, where modern therapeutic agents failed to treat (Molan, 2001). The antibacterial activity of honey has been attributed to high osmolarity, acidic $\mathrm{pH}$, hydrogen peroxide generation, and presence of other phytochemical constituents such as aromatic acids and phenolic compounds (Molan, 1992a,b). According to Molan (1992a), hydrogen peroxide is the major contributor to the antibacterial activity of honey, and the different levels of hydrogen peroxide in honey from different sources are responsible for their varying antibacterial effects. However, the presence of non-peroxide compounds in the honey also is believed to inhibit an extensive range of bacteria. Although all honey consists of similar nutritional profile but Taormina et al. (2001) reported that honey from different sources contain different levels of antibacterial activity, may due to varied geographical distribution and floral content. In spite of a vast research on the antibacterial property of honey in various parts of the world (AlNamma, 2009), to the best of our understanding the study on the potential antibacterial activity of Malaysian honey has not yet been properly documented. In this study, antibacterial activities of three different Malaysian monofloral honey samples were tested against nine strains of common human pathogenic bacteria.

\section{Materials and Methods \\ Honey samples and bacterial strains}

Monofloral honey of different floral sources namely Koompassia excelsa (Becc.) Taub (Tualang), Melaleuca cajuputi Powell (Gelam) and Durio zibethinus Murr. (Durian) were obtained from several geographical locations in Malaysia. Human pathogenic bacteria species such as grampositives: Staphylococcus aureus (ATCC6518 and ATCC25923), Staphylococcus epidermidis (ATCC12228), Enterococcus faecalis (ATCC12228), vancomycin-resistant enterococci (VRE) species: Enterococcus faecium (LMG16192) and Enterococcus faecalis (LMG16216); gram-negatives: Escherichia coli (ATCC25922), Salmonella enterica serovar Typhimurium (ATCC14028) and Klebsiella pneumoniae (ATCC13883) were provided by Faculty of Science, Universiti Tunku Abdul Rahman (UTAR), Malaysia.

\section{In-vitro antibacterial activity tests \\ Agar well-diffusion method}

Three to five bacterial colonies of 24-hour-old pure culture were suspended in $10 \mathrm{ml}$ nutrient broth. The turbidity of the suspension was adjusted to achieve $0.5 \mathrm{McFarland}$ (equivalent to that of $1.5 \times 10^{8} \mathrm{CFU} / \mathrm{ml}$ ) with the absorbance range of 0.08 to 0.13 by spectrophotometer at wavelength of $625 \mathrm{~nm}$ (Andrew, 2009). The bacterial suspension was then seeded evenly onto the surface of Mueller Hinton agar plates with a sterile 
http://dx.doi.org/10.4314/ajtcam.v11i2.14

swab. Each honey type was diluted in sterile distilled water to different concentrations of $20 \%, 40 \%, 60 \%, 80 \%$ (v/v) and $100 \%$ undiluted honey. Wells were cut using $6 \mathrm{~mm}$ diameter cork borer to which appropriate concentrations of honey and sterile distilled water (sterility control) were added. The plates were incubated at $37^{\circ} \mathrm{C}$ and examined after 24 hours incubation. All the tests were carried out in triplicate and the mean values were obtained.

\title{
Broth dilution method
}

The bacterial strains which were successfully inhibited by the tested honey in well-diffusion method were further tested for minimum inhibitory concentration (MIC). Appropriate volume of honey was added into nutrient broth and then serially twofold diluted to obtain varying concentrations of $2000 \mathrm{mg} / \mathrm{ml}, 1000 \mathrm{mg} / \mathrm{ml}, 500 \mathrm{mg} / \mathrm{ml}, 250 \mathrm{mg} / \mathrm{ml}, 125 \mathrm{mg} / \mathrm{ml}, 62.5 \mathrm{mg} / \mathrm{ml}, 31.25 \mathrm{mg} / \mathrm{ml}, 15.63 \mathrm{mg} / \mathrm{ml}$ and $7.81 \mathrm{mg} / \mathrm{ml} \mathrm{respectively}$. Then the adjusted $0.5 \mathrm{McFarland}$ bacterial suspension was added to each honey sample and incubated at $37^{\circ} \mathrm{C}$ for 24 hours, after which the tubes were checked macroscopically and compared with negative control to determine the lowest concentration of honey sample with no visible growth is determined as MIC (Agbeje et al., 2006). Tubes without visible growth or turbidity in MIC were then tested for minimum bactericidal concentration (MBC). The nutrient agar plates evenly seeded with $50 \mu \mathrm{l}$ of the culture from the tubes with no visual growth shown in the MIC test were incubated at $37^{\circ} \mathrm{C}$ for 24 hours. Lowest concentration without any visible growth of bacterial colony on plate was determined as MBC (Mohapatra et al., 2011). The assays were duplicated.

\section{Results}

From the preliminary screening, it was observed all tested Malaysian honey exhibited various degrees of inhibitory effect with the welldiffusion method. Formation of clear zones indicated the presence of potent antibacterial activity. Generally, more concentrated honey demonstrated higher antibacterial potency than the diluted honey. Koompassia excelsa (Tualang) honey showed antibacterial effect against all the tested bacteria including VRE (E. faecalis LMG16216 and E. faecium LMG16192) from 80\% (v/v) onwards with the strongest activity seen against S. enterica ser. Typhimurium ATCC14028 even in the lowest concentration 20\% (v/v) (Figure 1). Melaleuca cajuputi (Gelam) honey showed that it was more potent than Tualang honey as its inhibition of most of the tested bacteria started from $40 \%$ (v/v). It was effective against K. penumoniae ATCC13883, $S$. aureus ATCC6518 and S. epidermidis ATCC12228 and with a relatively strong potency against VRE and the rest (Figure 2). K. pneumoniae ATCC13883 was the most susceptible to the Durio zibethinus (Durian) honey followed by S. epidermidis ATCC12228 among the tested strains. However, it was merely effective against S. aureus ATCC25923, E. coli ATCC25922, E. faecalis ATCC29212 and S. enterica ser. Typhimurium ATCC14028 and totally ineffective against the rest (Figure 3). The minimum inhibitory concentration (MIC) and minimum bactericidal concentration (MBC) of the honey sample are shown in Table 1. It was observed that all the honey types, except Durian honey, exhibited substantial bactericidal activity to all the bacterial species. Based on the outcome, it was also observed that $S$. aureus ATCC6518 was the most sensitive to Gelam honey with the lowest MIC and MBC.

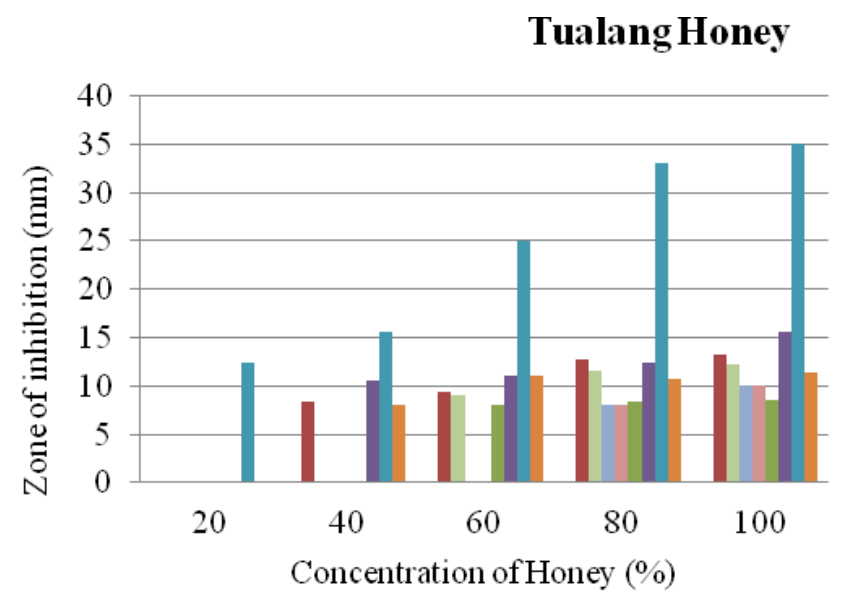

\author{
S.aureus ATCC6518 \\ - S.aureus ATCC25923 \\ S.epidermidis ATCC 12228 \\ E. faecium LMG16192 \\ E.faecalis LMG16216 \\ E.faecalis ATCC29212 \\ - E.coliATCC25922 \\ - S. enterica ser. Typhimurium \\ ATCC14028 \\ K pneumoniae ATCC13883
}

Figure 1: Zone of inhibition produced by Tualang honey against bacterial strains.

\section{Discussion}

In present study, Gelam honey from the source of Melaleuca cajuputi was able to exert inhibition and bactericidal effect against most bacterial strains and species including antibiotic-resistant strains, this proven its strongest antibacterial potential compare to honey from Koompassia excelsa (Tualang) and Durio zibethinus (Durian). From the outcome, concentration of honey used is directly proportional to inhibitory effect has indicated that antibacterial effect of honey works best in its undiluted form, where the conditions of antibacterial properties like acidity, osmolarity, and phytochemical components including flavonoids and phenolic content are well preserved (Badawy et al., 2004; Molan, 2001). However, as 
http://dx.doi.org/10.4314/ajtcam.v11i2.14

reported by Mundo et al. (2004), dilution of honey activates the activity of glucose oxidase which enhances hydrogen peroxide-mediated activity and this may be a possible explanation of the inhibitory potency of diluted honey on certain bacteria. The range of MIC and MBC values of honey correlated well with the results obtained using well-diffusion method that showed the strongest antibacterial potency of Gelam honey followed by Tualang and Durian honey.

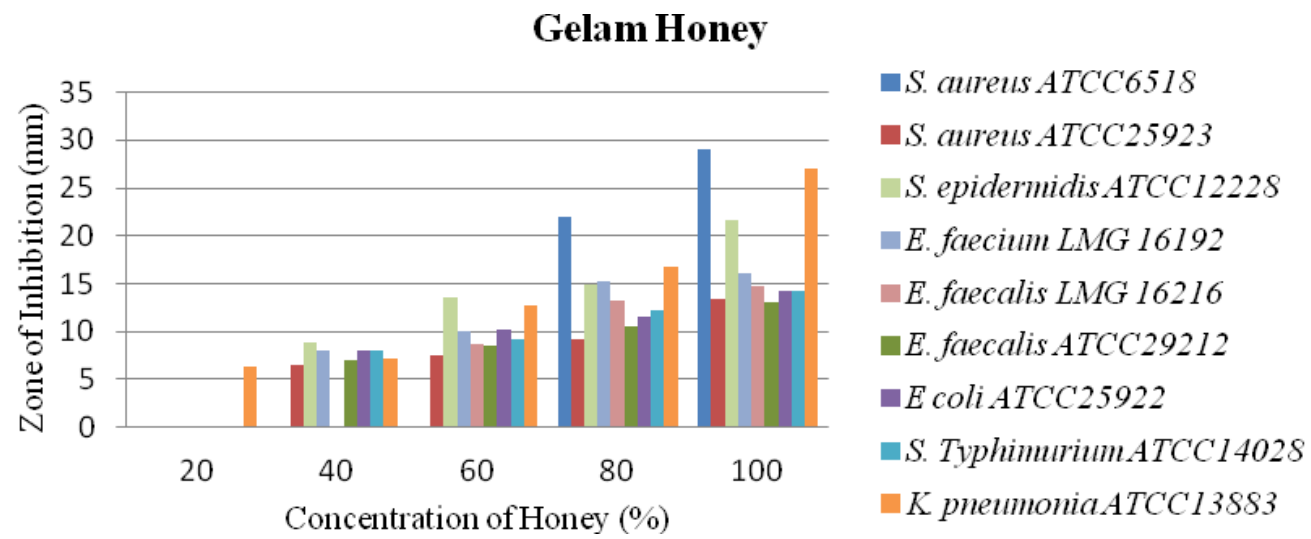

Figure 2: Zone of inhibition produced by Gelam honey against bacterial strains.

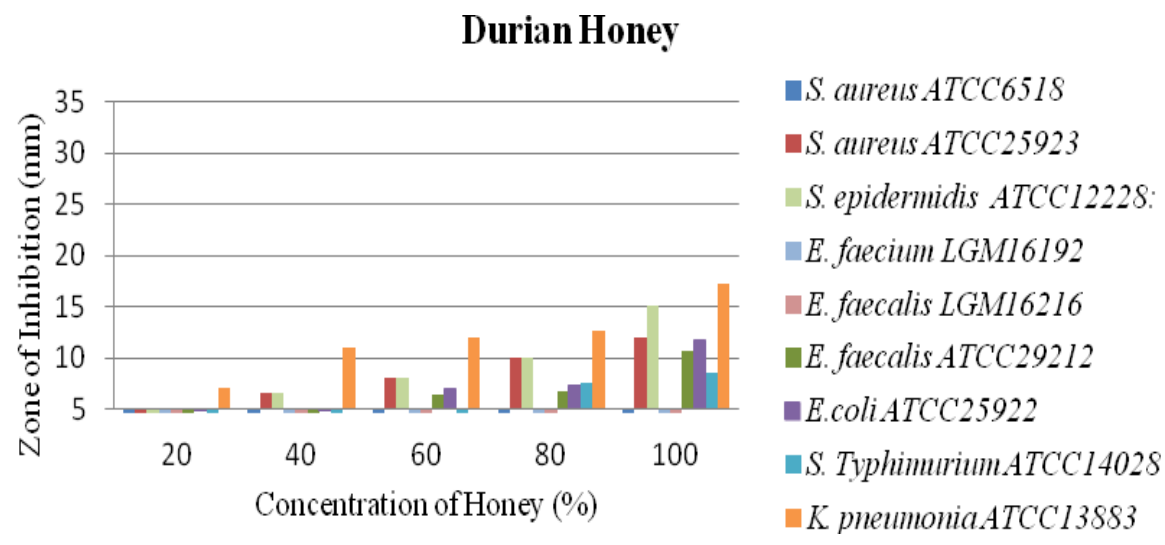

Figure 3: Zone of inhibition produced by Durian honey against bacterial strains.

Table 1: MIC and MBC (mg/ml) of three Malaysian honey.

\begin{tabular}{ccccccc}
\hline Bacterial strains & \multicolumn{2}{c}{ Tualang honey } & \multicolumn{2}{c}{ Gelam honey } & \multicolumn{2}{c}{ Durian honey } \\
& MIC & MBC & MIC & MBC & MIC & MBC \\
\hline S. aureus ATCC6518 & 500 & 2000 & 125 & 125 & 500 & 1000 \\
S. aureus ATCC25923 & 250 & 500 & 1000 & 1000 & 250 & 500 \\
S. epidermidis ATCC12228 & 250 & 1000 & 250 & 250 & 250 & 1000 \\
E. faecium LMG16192 & 250 & 2000 & 500 & 2000 & 500 & 2000 \\
E. faecalis LMG16216 & 250 & 2000 & 500 & 2000 & 500 & 2000 \\
E. faecalis ATCC12228 & 250 & 2000 & 1000 & 1000 & 500 & 2000 \\
E. coli ATCC25922 & 250 & 500 & 500 & 500 & 500 & NA \\
S. enterica ser. Typhimurium & 125 & 500 & 250 & 500 & 1000 & NA \\
ATCC14028 & & & & & & \\
K. pneumoniae ATCC13883 & 500 & 1000 & 125 & 250 & 125 & 250 \\
\hline
\end{tabular}

NA: No activity seen against the tested bacteria 
http://dx.doi.org/10.4314/ajtcam.v11i2.14

In the whole, higher susceptibility of gram-negative bacteria to honey was seen, in which $S$. enterica ser. Typhimurium inhibited the most by Tualang honey while K. pneumoniae was highly susceptible to the action of Durian honey. This indeed supported by Al-Namma (2009) and El-sukhon et al. (1994) who also observed that honey has a greater inhibitory effect on gram-negative bacteria compared to gram-positive bacteria. According to Taormina et al. (2001), the antibacterial activity of honey on gram-negative bacteria was attributed to the presence of several factors such as: high content of tetracycline derivatives, hydrogen peroxide and powerful antioxidants. On the other hand, the cell wall of gram-negative bacteria is more prone to mechanical breakage because of the low amount of peptidoglycan compared to gram-positives (Tortora et al., 2013).

In overall, observed inconsistent pattern of antibacterial potency in this study can be due to several reasons. One possibility might be related to the differences in sensitivity of each bacterial species to the inhibitory activity of honey used that reported by others (Ceyhan and Ugur, 2001; Taormina et al., 2001). In addition, the discrepancy of the antibacterial activity between honeys could due to the difference of chemical composition including sugar profile, glycerol, ethanol, as well as other physicochemical parameters which closely related to the variation of floral origin and geographical provenience (Molan, 1992b). Previous study also showed human pathogens including gram-positives, gram-negatives and fungi exhibited diverse sensitivities towards honey sample from different sources (Mercan et al., 2007).

The excellent antibacterial activity of Malaysian honey especially honey from $M$. cajuputi (Gelam) against these human pathogens indicates the usefulness of honey as an antibacterial agent. These honey samples could have potential applications in foods to spoilage microorganisms or pathogens to enhance the safety of foods. Nevertheless, further in-depth studies are necessary including the identification and characterization of the related active components that may suggest any possible therapeutic potential.

\section{Acknowledgements}

The authors would like to acknowledge the faculty for equipments and instrumental facilities.

\section{References}

1. Agbeje, E.O., Ogunsanya, T. and Aiwerioba O.I.R. (2006). Conventional use of honey as antibacterial agent. Analysis of African Medicine Journal, 5(2), 78-81.

2. Al-Namma, R.T. (2009). Evaluation of in vitro inhibitory effect of honey on some microbial isolate. Journal of Bacteriology Research, 1(6): 64-67.

3. Andrew, J.M. (2009). BSAC standardized disc susceptibility testing method (version 8). Journal of Antimicrobial Chemotherapy, 64: 454-489.

4. Badawy, O.F.H., Shafii, S.S.A., Tharwat, E.E. and Kamal, A.M. (2004). Antibacterial activity of bee honey and its therapeutic usefulness against Escherichia coli and Salmonella typhimurium infection. Review of Science and Technology, 23: 1011-1122.

5. Ceyhan, N. and Ugur, A. (2001). Investigation of in vitro antimicrobial activity of honey. Biology Forum, 94(2): 363-371.

6. Dustmann, J.H. (1979). Antibacterial effect of honey. Apiacta, 14(1): 7-11.

7. El-Sukhon, S.N., Abu-Harfeil, N. and Sallal, A.K. (1994). Effects of honey on bacterial growth and spore germination. Journal of Food Protocols, 57(10): 918-920.

8. Mercan, N., Guvensen, A., Celik, A. and Katircioglus, H. (2007). Antimicrobial activity and pollen composition of honey samples collected from different provinces in Turkey. Natural Product Research, 21(3): 187-195.

9. Mohapatra, D.P., Thakur, V. and Brar, S.K. (2011). Antibacterial efficacy of raw and processed honey. Biotechnology Research International, 2011: 1-6.

10. Molan, P.C. (1992a). The antibacterial activity of honey 1. The nature of the antibacterial activity. Bee World, 73(1): 5-28.

11. Molan, P.C. (1992b). The antibacterial activity of honey 2. Variation in the potency of the antibacterial activity. Bee World, 73(2): 59-76.

12. Molan, P.C. (2001). Why honey is effective as a medicine 2. The scientific explanation of its effects. Bee World, 82(1): 22-40.

13. Mundo, M.A., Padilla-Zakour, O.I. and Worobo, R.W. (2004). Growth inhibition of food borne pathogens and food spoilage organisms by select raw honeys. International Journal of Food Microbiology, 97(1): 1-8.

14. Tortora, G.J., Funke, B.R. and Case, C.L. (2013). Microbiology. An introduction. United States of America: Pearson Education, Inc. Illinois, 8488 .

15. Taormina, P.J., Niemira, B.A. and Bauchat, L.R. (2001). Inhibitory activity of honey against food borne pathogens as influenced by the presence of hydrogen peroxide and level of antioxidant power. International Jornal of Food Microbiology, 69: 217-225. 